\title{
Viability and Vigor of Osmotically Primed Muskmelon Seeds After Nine Years of Storage
}

\author{
Melkizedek O. Oluoch and Gregory E. Welbaum \\ Department of Horticulture, Virginia Polytechnic Institute and State University, \\ Blacksburg VA, 24061-0327
}

Additional index words. Cucumis melo, germination

\begin{abstract}
The viability and vigor of osmotically primed ( 0.3 м KNO, 6 days, 25C) and nonprimed 'PMR 45' muskmelon (Cucumis melo $\mathrm{L}$.) seeds were compared after storage for 9 years at $<20 \mathrm{C}$ and $6 \%$ moisture content (MC, dry weight basis). Viability was compared at 20,25 , and $30 \mathrm{C}$ at water potentials of $0,-0.2,-0.4,-0.6$, and $-0.8 \mathrm{MPa}$ and in soil. Additionally, stored primed and nonprimed seeds were either primed, aged (15\% MC and 45C) for up to 8 days, or aged for 72 hours and primed. The force required to puncture 5-mm-long, micropylar seed pieces was measured using an Instron universal testing machine. Less force was required to puncture primed seed pieces at $0,5,15,20$, and 25 hours of imbibition, demonstrating that osmotic priming weakens the perisperm envelope tissue that the radicle must penetrate for germination to occur. In an earlier report, germination rate and final germination percentages were higher for osmotically primed seeds both in laboratory tests and field emergence studies conducted immediately after priming. After 9 years in storage, nonprimed seeds germinated to higher percentages in water at $30 \mathrm{C}$ and reduced water potential at all temperatures, while primed seeds germinated to higher percentages in water at 20 and $25 \mathrm{C}$ and exhibited a higher percentage of seedling emergence at a soil MC of $17 \%$. Priming durations of $\leq 5$ days had no effect on the viability, while longer durations decreased the viability of stored primed and nonprimed seeds. Priming generally decreased the log mean time to germination of stored nonprimed seeds but increased values for stored primed seeds. Controlled deterioration increased the log mean time to germination and decreased the viability of primed seeds faster than nonprimed seeds. Priming following controlled deterioration had no effect on nonprimed seeds and reduced the percent viability of primed seeds by $20 \%$. Osmotic priming has a deleterious effect on the seed storage life of muskmelon seeds.
\end{abstract}

Seed priming or osmotic conditioning is a controlled hydration treatment that allows pregerminative metabolic activity to proceed but prevents radicle emergence. Primed seeds can be dried and upon rehydration may exhibit faster rates of germination, greater tolerance to environmental stress, and reduced dormancy (Bradford, 1986; Khan, 1992). However, the effect of priming on the storage life of seeds remains unclear.

In some studies, priming treatments did not adversely affect the storage life of seeds. Primed carrot and leek seeds retained their enhanced vigor after storage for 450 days (Dearman et al., 1987b). The improved germination performance of primed spinach seeds was retained after 30 days of storage at $5 \mathrm{C}$ (Atherton and Farooque, 1983). A short hydration treatment applied to wheat seeds had little effect on germinability during storage, while longer hydration treatments increased the susceptibility to deterioration (Nath et al., 1991). Dearman et al. (1986), reported that primed and dried onion seeds stored at 10C and 9\% moisture content (MC) maintained a faster rate of germination after 18 months in storage.

Other studies have shown that primed seeds have decreased storage life. Tomato (Alvarado and Bradford, 1988; Argerich et al., 1989; Owen and Pill, 1994) and wheat (Nath et al., 1991) seeds exhibited reduced storage life following priming. Prehydration treatments in water for $<1 \mathrm{~h}$ had little effect on the rate of germination or storage life of lettuce seeds, but increasing the duration of either priming or prehydration reduced the mean time to germination or seed longevity by as much as $84 \%$ compared to nonprimed seeds (Tarquis and Bradford, 1992).

Received for publication 18 May 1995. Accepted for publication 22 Nov. 1995. We thank Kent J. Bradford for providing the seeds for this experiment and James $\mathrm{H}$. Wilson for assistance with Instron analysis. This research was funded in part by USDA research project W-168. Use of trade names does not imply endorsement of products named nor criticism of similar ones not named. The cost of publishing this paper was defrayed in part by the payment of page charges. Under postal regulations, this paper therefore must be hereby marked advertisement solely to indicate this fact.
Muskmelon seeds showed a differential response to osmotic priming among seed lots (Bradford et al., 1988; Welbaum and Bradford, 1991a). The effects of priming were greater on newly matured seeds than on older seeds (Welbaum and Bradford, 1991a). Since newly matured muskmelon seeds reach maximum vigor after a period of dry storage called afterripening, priming may enhance vigor by substituting for afterripening (Welbaum and Bradford, 1991a). Short-term aging treatments mimic afterripening and increase the vigor of newly matured seeds similar to priming treatments (Welbaum and Bradford, 1991b). Therefore, priming may also age muskmelon seeds decreasing their storage life compared to nonprimed seeds. To test this hypothesis, we examined the performance of primed and nonprimed muskmelon seed lots stored for 9 years at less than 20C and 6\% MC. Germination performance after storage was compared with germination and field emergence results in an earlier study conducted immediately after priming (Bradford et al., 1988). In addition, the strength of the perisperm envelope tissue surrounding the embryonic axis was tested at six time intervals during imbibition using an Instron universal testing machine to determine whether osmotic priming decreases the resistance of the perisperm envelope to radicle emergence.

\section{Materials and Methods}

Priming treatments and storage conditions. Muskmelon('PMR 45', Petoseed Co.) seeds were primed in February 1984 for 6 days in the dark at $25 \mathrm{C}$ in an aerated $0.3 \mathrm{M} \mathrm{KNO}_{3}$ solution (Bradford et al., 1988). Seeds were dried to a MC of 6.6 and $6.0 \%$ for primed and nonprimed seeds, respectively, and stored in tightly sealed plastic bottles at $20 \mathrm{C}$ for the first 4 years and then at $5 \mathrm{C}$ for the final 5 years. Primed and nonprimed seeds were primed at $25 \mathrm{C}$ in an aerated 0.3 м $\mathrm{KNO}_{3}$ solution as described above at the end of the storage period. Seeds were redried in a desiccator to a MC of $6 \%$. Seed MC was expressed as a percentage of the dry weight after heating in an 
Table 1. Germination of primed and nonprimed seeds at five water potentials ( $\Psi \mathrm{s})$ and three temperatures after 9 years of storage. Means were calculated from laboratory germination tests conducted for 21 days using three replications of 25 seeds each. The mean log time to germination (log $\bar{t}$ ) was calculated using probit analysis for treatments with $>20 \%$ germination. ANOVA was performed on arcsine-transformed percentage data and actual percentages are shown.

\begin{tabular}{|c|c|c|c|c|c|c|c|c|c|c|c|c|c|c|c|}
\hline \multirow[b]{4}{*}{ Seed treatment } & \multicolumn{15}{|c|}{ Temp } \\
\hline & \multicolumn{5}{|c|}{$20 \mathrm{C}$} & \multicolumn{5}{|c|}{$25 \mathrm{C}$} & \multicolumn{5}{|c|}{$30 \mathrm{C}$} \\
\hline & \multicolumn{5}{|c|}{$\Psi(\mathrm{MPa})$} & \multicolumn{5}{|c|}{$\Psi(\mathrm{MPa})$} & \multicolumn{5}{|c|}{$\Psi(\mathrm{MPa})$} \\
\hline & 0 & 0.2 & 0.4 & 0.6 & 0.8 & 0 & 0.2 & 0.4 & 0.6 & 0.8 & 0 & 0.2 & 0.4 & 0.6 & 0.8 \\
\hline \multicolumn{16}{|l|}{ Germination (\%) } \\
\hline Primed & 81 & 32 & 3 & 0 & 0 & 87 & 75 & 20 & 5 & 0 & 77 & 92 & 26 & 20 & 11 \\
\hline $\begin{array}{l}\text { Nonprimed } \\
\log t(h)\end{array}$ & 73 & 29 & 20 & 0 & 0 & 72 & 60 & 45 & 20 & 9 & 91 & 84 & 40 & 38 & 20 \\
\hline Primed & 2.33 & 2.99 & --- & --- & --- & 2.37 & 2.68 & --- & --- & --- & 2.35 & 2.25 & 3.29 & --- & --- \\
\hline Nonprimed & 2.43 & 2.97 & --- & --- & --- & 2.55 & 2.57 & 2.88 & --- & --- & 2.40 & 2.30 & 3.41 & 3.54 & --- \\
\hline \multicolumn{16}{|c|}{ Mean separation: $\operatorname{LSD}_{0.5}$, germination $\%=7 ; \log \bar{t}=0.26$} \\
\hline$\overline{\text { Water potential }(\Psi)}$ & & & & & & & & $* * *$ & & & & & $* * *$ & & \\
\hline Seed treatment $(\mathrm{P})$ & & & & & & & & $*$ & & & & & NS & & \\
\hline Temperature $(\mathrm{T})$ & & & & & & & & $* * *$ & & & & & NS & & \\
\hline$\Psi \times \mathrm{P}$ & & & & & & & & $* *$ & & & & & NS & & \\
\hline $\mathrm{T} \times \Psi$ & & & & & & & & $* * *$ & & & & & $* *$ & & \\
\hline $\mathrm{T} \times \mathrm{P}$ & & & & & & & & NS & & & & & NS & & \\
\hline $\mathrm{T} \times \Psi \times \mathrm{P}$ & & & & & & & & $*$ & & & & & NS & & \\
\hline
\end{tabular}

${ }_{\mathrm{z} F}$ test results.

Ns,*,**,*** Nonsignificant or significant at $P=0.05,0.01$, or 0.001 , respectively.

oven at $130 \mathrm{C}$ for $1 \mathrm{~h}$ (International Seed Testing Association, 1985).

Laboratory germination. Three replicates of 25 seeds each were placed in $9 \times 9 \times 1.5-\mathrm{cm}$ transparent, covered, plastic boxes (Falcon 1012; Becton Dickinson and Co., Lincoln Park, N.J.) on two thicknesses of germination blotter paper (Anchor Paper Co., Hudson, Wis.). The blotters were saturated with $12 \mathrm{~cm}^{3}$ deionized water or solutions of PEG 8000 with $\Psi$ s ranging from 0 to -0.8 MPa in 0.2-MPa increments prepared according to Michel (1983). Plastic boxes were placed in self-sealing plastic bags (Ziploc; Dow Brands L.P.) to reduce evaporation. The $\Psi$ s of the blotters were verified by osmometry (model 5500; Wescor, Logan, Utah) 3 to 4 days after the start of incubation and were uniformly 0.2 to $0.4 \mathrm{MPa}$ lower than the initial $\Psi$ s due to the concentrating effect of imbibition and evaporation from the boxes during seed scoring. For convenience, the initial $\Psi$ s are given. The boxes containing seeds were placed in dark incubators maintained at 20,25, and $30 \pm 1 \mathrm{C}$, and germinated seeds were removed from boxes at 12 -h intervals for 21 days.

Controlled deterioration. One hundred seeds were incubated in $7.5 \times 1.0-\mathrm{cm}$ plastic vials for $24 \mathrm{~h}$ with the precise amount of water to raise the MC to $15 \%$. Vials were uniformly submerged in a water bath at $45 \mathrm{C}$ for up to 8 days. The seeds were removed from each vial and slowly dried in a desiccator maintained at $45 \%$ RH for 7 days at $20 \mathrm{C}$ before germination testing in blotters saturated with 11 $\mathrm{cm}^{3}$ of deionized water. Some samples of primed and nonprimed seeds were aged for $72 \mathrm{~h}$ and immediately primed for 6 days, redried to a MC of $6 \%$, and stored for $24 \mathrm{~h}$ before germination testing. Germination testing of aged and reprimed seeds was conducted at $25 \mathrm{C}$ using four replicates of 25 seeds each as described above.

Seedling emergence. Metal flats $(50 \times 35 \times 8 \mathrm{~cm})$ were uniformly packed with Hayter Loam (fine-loamy, mixed, mesic, Ultic Hapludaf) soil, hydrated to field capacity $(21 \% \mathrm{MC})$ and sealed in plastic bags to prevent moisture loss. Some flats were dried to 19 and $17 \%$ MC. Soil MC was determined by heating samples in an oven for $2 \mathrm{~h}$ at $105 \mathrm{C}$. Muskmelon seeds were planted by hand 2.5 $\mathrm{cm}$ deep with 25 seeds of each treatment to a flat. There were three replications (flats) for each soil MC. Seedling emergence was scored at 24-h intervals for 21 days. The experiment was conducted in a greenhouse with air temperatures ranging from 13 to $23 \mathrm{C}$ with a mean of $19 \mathrm{C}$.

Instron analysis. The mechanical resistance of the micropylar perisperm envelope tissue surrounding the radicle was measured on decoated seed pieces cut $5 \mathrm{~mm}$ above the tip of the embryonic axis. A seed tip (embryonic axis and perisperm envelope) was mounted in a wooden holder placed on a 20-N load cell of an Instron universal testing machine (model 1123; Instron Engineering Corp., Canton, Mass.). The crosshead of the Instron was fitted with a tapered steel needle with a tip diameter of $0.24 \mathrm{~mm}$ that approximated the size and shape of the radicle. The needle was lowered through the sample at a rate of $5 \mathrm{~mm} \cdot \mathrm{min}^{-1}$ and advanced without resistance through a hole in the center of the sample holder (Welbaum et al., 1995). The penetration force for the perisperm envelope was determined from the peak of the load-deflection curve. At least 20 individual primed, nonprimed, and nonprimed boiled (control) seeds were measured at each time interval and expressed as means \pm SE.

Statistical analysis. Probit analysis was used to determine the log mean time and the variance of germination. When germination percentages were plotted on a probit scale versus log time $(t)$, straight lines of approximately equal slope were produced for different treatments, indicating a normal distribution of germination events with log time (Finney, 1970). The log mean time to germination $(\log \bar{t})$ was determined graphically from the intersection of the least squares regression line of $\log \bar{t}$ versus probit germination percentage and 50\% germination for treatments with greater than $20 \%$ germination. The slope of a probit plot is equal to the inverse standard deviation $(\sigma)$ (Finney, 1970). Linear regression was used to compare slopes of the plot of probit viability 
Table 2. Seedling emergence percentage and mean $\log$ time to emergence $(\log \bar{t})$ of primed and nonprimed muskmelon seeds at three soil moisture contents in a greenhouse after 9 years of storage.

\begin{tabular}{|c|c|c|c|c|c|c|}
\hline \multirow{2}{*}{$\begin{array}{l}\text { Seed } \\
\text { treatment }\end{array}$} & \multicolumn{6}{|c|}{ Soil moisture content $(\%)$} \\
\hline & 17 & 19 & 21 & 17 & 19 & 21 \\
\hline & \multicolumn{3}{|c|}{ Seedling emergence $(\%)^{z}$} & \multicolumn{3}{|c|}{$\log \bar{t}(h)$} \\
\hline Primed & 73 & 24 & 0 & 2.31 & 3.14 & --- \\
\hline Nonprimed & 56 & 15 & 0 & 2.36 & 3.30 & --- \\
\hline \multicolumn{7}{|c|}{$\operatorname{LSD}_{0.05}$, germination $\%=14 ; \log \bar{t}=0.4$} \\
\hline
\end{tabular}

${ }^{\mathrm{z}}$ Seedling emergence percentages were arcsine-transformed before analysis and actual percentages are shown. Means were calculated from three replications of 25 seeds each.

versus aging time to analyze the rate of deterioration of primed and nonprimed seeds (Ellis and Roberts, 1981). The significance of main effects of $\Psi$ s, seed treatment, and temperature for arcsintransformed germination percentages, $\log \bar{t}$, and $\sigma$ were compared

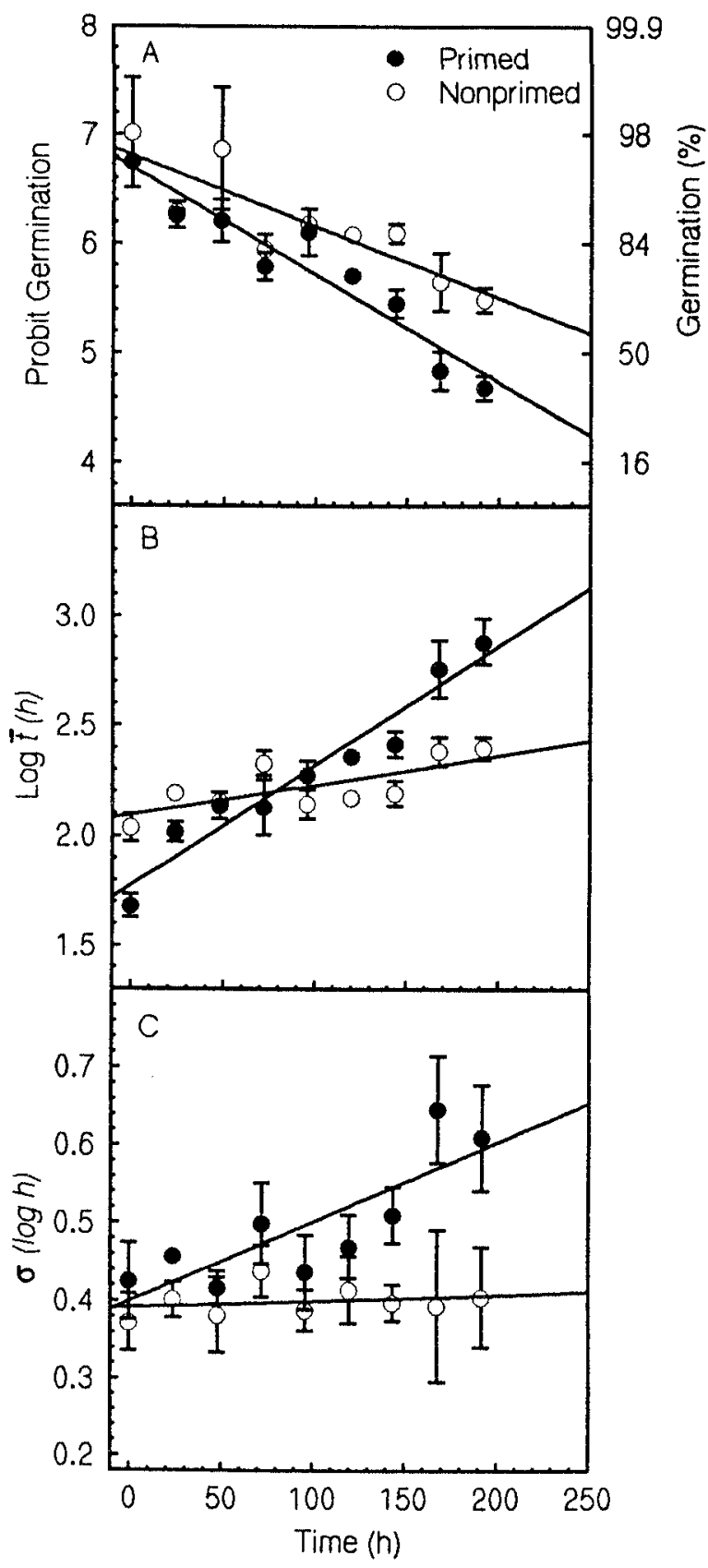

by ANOVA (CoStat; CoHort Software, Minneapolis). Data for actual germination percentages are shown.

\section{Results}

Germination at different temperatures and $\Psi$ s. Germination percentages of nonprimed seeds were highest in water at $30 \mathrm{C}$ and declined by $20 \%$ at $25 \mathrm{C}$ and $20 \mathrm{C}$ (Table 1). The germination percentages of primed seeds were highest in water at $25 \mathrm{C}$ and lowest at 30C (Table 1). Primed seeds germinated at higher percentages in water compared to nonprimed seeds at $20 \mathrm{C}$ and $25 \mathrm{C}$ but not at 30C. $\log \bar{t}$ was essentially the same for nonprimed and primed seeds in water at all temperatures (Table 1).

Germination percentages for nonprimed seeds declined with decreasing $\Psi$ s (Table 1). Seeds were more sensitive to reduced $\Psi$ s at low temperature than at high temperature. Reduced $\Psi$ s had a similar effect on the germination percentage of primed seeds, but at most $\Psi$ s and temperatures the germination percentage of primed seeds was lower than nonprimed seeds (Table 1). The $\Psi$ s needed to inhibit germination by $50 \%$ for primed and nonprimed seeds were -0.25 and $-0.33 \mathrm{MPa}$, respectively, at $30 \mathrm{C}$ and were not significantly different (data not shown). $\log \bar{t}$ also declined with $\Psi \mathrm{s}$, and there were no differences between the values for primed and nonprimed seeds (Table 1). After 4 days at $25 \mathrm{C}$, mean root lengths for nonprimed and primed seeds were $53 \mathrm{~mm}$ and $62 \mathrm{~mm}$ respectively, and not significantly different (data not shown).

Seedling emergence. In a greenhouse, seedlings from stored primed or nonprimed seeds failed to emerge in soils saturated to field capacity (21\% MC) (Table 2). As soil MC declined, emergence percentages increased. At $17 \%$ soil MC, seedlings from primed seeds emerged at a higher percentage than from nonprimed seeds. Seedling emergence was fastest at $17 \%$ soil MC and there was no difference in $\log t$ for primed and nonprimed seeds (Table 2).

Germination after controlled deterioration. The germination percentages of primed and nonprimed seeds were similar before aging treatments were applied (Fig. 1A). During controlled deterioration, primed seeds lost viability more rapidly than nonprimed seeds. The time required to reduce the germination percentage of primed seeds to $50 \%$ was $180 \mathrm{~h}$ compared to $290 \mathrm{~h}$ for nonprimed seeds.

Fig. 1. Effects of controlled deterioration on primed $(\bullet)$ and nonprimed $(\bigcirc)$ seed germination percentage plotted on a probit scale (A); mean log time to germination, $\log \bar{t},(\mathbf{B})$; and the standard deviation of germination, $\sigma,(\mathbf{C})$. The regression equations and $\pm \mathrm{SE}$ of the slopes are as follows: (A) primed, $\mathrm{y}=6.70+-0.010 \mathrm{x}$ $( \pm 0.001), r^{2}=0.91$; nonprimed, $\mathrm{y}=6.81+-0.007 \mathrm{x}( \pm 0.001), r^{2}=0.74 ;(\mathbf{B})$ primed, $\left.\mathrm{y}=1.78+0.005 \mathrm{x}( \pm 0.001), r^{2}=0.94\right)$; nonprimed, $\mathrm{y}=2.09+0.001 \mathrm{x}$ $\left( \pm 4.8^{-4}\right), r^{2}=0.53 ;(\mathbf{C})$ primed, $\left.\mathrm{y}=0.40+0.001 \times\left( \pm 0.7^{-4}\right), r^{2}=0.68\right)$; nonprimed, $\mathrm{y}=0.39+8.06^{-5} \mathrm{x}\left( \pm 1.1^{-4}\right), r^{2}=0.76$. Each point is the mean of four replicates and the error bars indicate \pm SE. 
Table 3. The effect of priming $\left(0.3 \mathrm{M} \mathrm{KNO}_{3}\right)$ for up to 12 days on germination percentage, mean log time to germination (log $\left.\bar{t}\right)$, and standard deviation $(\sigma)$ of primed and nonprimed seeds after 9 years of storage. Germination was tested at $25 \mathrm{C}$ for 21 days.

\begin{tabular}{|c|c|c|c|c|c|c|c|c|c|c|}
\hline \multirow{2}{*}{$\begin{array}{l}\text { Prestorage } \\
\text { treatment }\end{array}$} & \multicolumn{10}{|c|}{ Duration of priming (days) } \\
\hline & 0 & 4 & 5 & 6 & 7 & 8 & 9 & 10 & 11 & 12 \\
\hline \multicolumn{11}{|c|}{ Germination \%** } \\
\hline Primed & $100^{z}$ & 89 & 95 & 81 & 88 & 88 & 73 & 68 & 79 & 52 \\
\hline Nonprimed & 96 & 100 & 96 & 84 & 99 & 96 & 83 & 89 & 79 & 72 \\
\hline \multicolumn{11}{|c|}{$\log \bar{t}(\mathrm{~h})^{* * * *}$} \\
\hline Primed & 1.58 & 1.72 & 1.60 & 1.80 & 1.70 & 1.73 & 1.88 & 2.13 & 2.03 & 2.18 \\
\hline Nonprimed & 1.90 & 1.76 & 1.58 & 1.63 & 1.62 & 1.55 & 1.79 & 1.75 & 1.89 & 1.90 \\
\hline \multicolumn{11}{|c|}{$\sigma(\log \mathrm{h})^{\mathrm{Ns}}$} \\
\hline Primed & 0.79 & 0.47 & 0.33 & 0.42 & 0.37 & 0.43 & 0.33 & 0.36 & 0.46 & 0.56 \\
\hline Nonprimed & 0.46 & 0.38 & 0.16 & 0.45 & 0.41 & 0.38 & 0.41 & 0.44 & 0.37 & 0.40 \\
\hline
\end{tabular}

${ }^{\mathrm{z} A N O V A}$ was performed on arcsine-transformed percentage data and actual percentages are shown. Means were calculated from three replications of 25 seeds each.

Ns,**,****N Nonsignificant or significant at $P=0.01$ or 0.001 , respectively, for the $\mathrm{F}$ test of stored primed versus nonprimed seeds across all priming durations.

Before controlled deterioration, primed seeds had a shorter log $t$ than nonprimed seeds (Fig. 1B). However, $\log t$ increased during controlled deterioration at a faster rate for primed seeds, and after $200 \mathrm{~h}$ of aging $\log t$ of primed seeds was significantly greater than for nonprimed seeds.

The $\sigma$ of germination for both primed and nonprimed seeds were similar before controlled deterioration treatments (Fig. 1C). However, as the duration of the controlled deterioration treatment increased the $\sigma$ of primed seeds also increased, while the $\sigma$ of nonprimed seeds remained constant.

Priming after storage. Stored primed and nonprimed seed lots were primed in an attempt to restore lost vigor and viability. Germination percentages of nonprimed seeds remained constant for priming durations of up to 8 days and then declined (Table 3 ). Repriming primed seeds reduced viability at all durations except 5 days (Table 3 ).

$\log \bar{t}$ for primed seeds remained the same or increased after repriming (Table 3 ). However, priming nonprimed seeds for 5 to 8 days decreased $\log \bar{t}$ (Table 3 ). The $\sigma$ was not consistently altered by priming stored primed and nonprimed seeds (Table 3).
Priming after controlled deterioration. Some nonprimed and primed stored seeds were subjected to controlled deterioration tests for 3 days before priming. Accelerated aging decreased germination percentages, increased $\log \bar{t}$, and had little effect on $\sigma$ for primed and nonprimed seeds, although accelerated aging reduced the performance of primed seeds more substantially than nonprimed seeds (Table 4). Priming had no effect on the germination percentage of aged nonprimed seeds (Table 4). However, repriming primed seeds following controlled deterioration decreased the germination percentage from $80 \%$ to $69 \%$. Priming did not affect $\log \bar{t}$ for either treatment. Priming after controlled deterioration had no effect on the $\sigma$ of stored primed and nonprimed seeds (Table 4).

Instron analysis. The penetration force was highest in dry seeds and declined sharply during the first few hours of hydration (Fig. 2). The force needed to penetrate nonprimed seed was consistently higher than primed seed throughout the imbibition time course, indicating that priming weakened the perisperm. Primed seeds first germinated at $25 \mathrm{~h}$, and the force required to puncture primed seed piece was $0.97 \mathrm{~N}$ compared to $1.27 \mathrm{~N}$ for nonprimed seed, which initially germinated at $28 \mathrm{~h}$ (Fig. 2).

Table 4. The effect of controlled deterioration ( $15 \% \mathrm{MC}$ and $45 \mathrm{C}$ for $72 \mathrm{~h}$ ) and priming ( 6 days, $0.3 \mathrm{M} \mathrm{KNO}_{3}$ ) followed by germination percentage, mean $\log$ time to germination $(\log \bar{t})$, and standard deviation $(\sigma)$ of primed and nonprimed seeds after 9 years of storage. Germination was tested at $25 \mathrm{C}$ for 21 days.

\begin{tabular}{|c|c|c|c|}
\hline \multirow{2}{*}{$\begin{array}{l}\text { Prestorage } \\
\text { treatment }\end{array}$} & \multicolumn{3}{|c|}{ Treatment } \\
\hline & Control & Aged & Aged + primed \\
\hline \multicolumn{4}{|c|}{ Germination $\%$ *** } \\
\hline Primed & $96^{\mathrm{z}}$ & 80 & 69 \\
\hline Nonprimed & 94 & 86 & 89 \\
\hline \multicolumn{4}{|c|}{$\log \bar{t}(\mathrm{~h})^{* * *}$} \\
\hline Primed & 1.68 & 2.12 & 2.17 \\
\hline Nonprimed & 2.04 & 2.26 & 2.34 \\
\hline \multicolumn{4}{|c|}{$\sigma(\log \mathrm{h})^{N s}$} \\
\hline Primed & 0.43 & 0.41 & 0.57 \\
\hline Nonprimed & 0.37 & 0.39 & 0.40 \\
\hline \multicolumn{4}{|c|}{$\mathrm{LSD}_{0.05}$, germination $\%=5 ; \log \bar{t}=0.12$} \\
\hline
\end{tabular}




\section{Discussion}

Osmotic priming in salt solutions provides little enhancement of germination in some species (Khan, 1992). Salt solutions are generally less effective than other priming agents because the high salt concentrations can damage embryos (Khan, 1992). In muskmelon seeds, osmotic priming in salt solutions significantly improves germination rate and germination percentages at low temperature and water potential (Nerson and Govers, 1986; Bradford et al., 1988; Welbaum and Bradford, 1991a). The endosperm and perisperm tissue in muskmelon seeds form a protective envelope around the embryo (Welbaum and Bradford, 1990). The small pore size of the perisperm cell wall acts as a molecular sieve allowing water to pass but not $\mathrm{K}^{+}$or other ions of similar size (Welbaum and Bradford, 1990). Muskmelon seeds are not damaged by priming in salt solutions because ions are excluded from the embryo by the perisperm envelope. The osmotic potential inside developing muskmelon fruits approximates an osmotic priming solution (Welbaum and Bradford, 1991a). Osmotically primed immature seeds germinate with the same vigor as fully mature seeds because developmental processes continue during priming (Welbaum and Bradford, 1991a). Therefore, the more rapid loss of vigor and viability by osmotically primed seeds during the 9 years of storage and controlled deterioration experiments was not likely due to embryo damage from salts in the priming solution.

In laboratory germination tests conducted at $18 \mathrm{C}$ immediately after priming, germination rate and final germination percentages were higher for primed seeds (Bradford et al., 1988). Seedling emergence from sterilized soil in flats under ambient outdoor temperatures ( 7 to 23C) was also improved by priming (Bradford et al., 1988). Primed seeds emerged more rapidly or showed increased final emergence percentages in five of seven field trials in two locations (Bradford et al., 1988).

After storage for 9 years at $<6.6 \mathrm{MC}$ and $<20 \mathrm{C}$, primed seeds exhibited higher final seedling emergence percentages in soil at $17 \%$ MC but not at other soil moisture contents (Table 2). $\log \bar{t}$ for seedling emergence in soil did not differ between treatments. At reduced $\Psi$ or at high temperature, there was either no difference between treatments or nonprimed seeds outperformed primed seeds (Table 1). During controlled deterioration, primed seeds lost viability faster and $\sigma$ and $\log \bar{t}$ increased more rapidly than for nonprimed seeds (Fig. $1 \mathrm{~A}-\mathrm{C}$ ). When results of germination tests

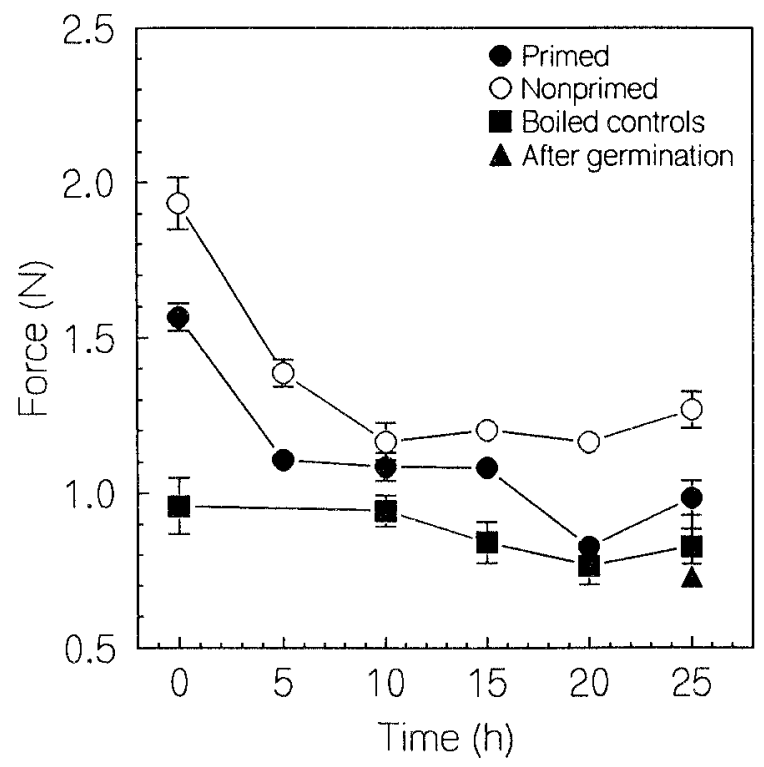

conducted after 9 years of storage are compared to those in the original study where osmotically primed seeds were clearly superior by most criteria, it is apparent that primed muskmelon seeds lost viabilty and vigor more rapidly than nonprimed seeds during long-term storage (Tables 1-4). Additionally, when compared to nonprimed seeds, primed muskmelon seeds also lost viability more rapidly, germinated more slowly, and lost uniformity more quickly following controlled deterioration experiments (Fig. 1). Our results along with studies of tomato (Alvarado and Bradford, 1988; Argerich et al., 1989; Owen and Pill, 1994), wheat (Nath et al., 1991), and lettuce (Tarquis and Bradford, 1992) indicate that priming before storage is deleterious to seed longevity in some species.

Differences between the seed testing procedures may explain some of the conflicting results among previous studies of the effect of priming on seed storage life. When the performance of primed and nonprimed stored seeds was compared at several temperatures and $\Psi$ s, using germination rate, or using accelerated aging tests, it has been concluded that primed seeds deteriorated more rapidly (Alvarado and Bradford, 1988; Argerich et al., 1989; Dearman et al., 1987a; Tarquis and Bradford, 1992). However, when comparisons were made after short-term storage or based on germination percentages from tests conducted under optimum conditions, priming did not appear to adversely affect seed storage life (Atherton and Farooque, 1983; Burgass and Powell, 1984; Dearman et al., 1987b). In this study, standard laboratory germination tests, soil emergence, and controlled deterioration tests indicate that osmotically primed muskmelon seeds have reduced storage life compared to nonprimed seeds.

Previous studies with tomato seeds showed that the mean time to germination increases logarithmically as viability declines during controlled deterioration (Argerich et al., 1989). Muskmelon seeds show a similar relationship (Fig. 1 A and B). Thus changes in germination rate, seed viability, and seed deterioration during storage are closely correlated. The delay in germination that occurs as seeds deteriorate is presumably related to the damage accumulated during storage. One of the reported benefits of priming is to repair damage incurred during storage, which would also improve the vigor of aged seeds (Dearman et al., 1986; Rao et al., 1987; Ward and Powell, 1983). However, in this study repriming stored primed seeds resulted in either no effect or further losses in viability which is inconsistent with the repair hypothesis (Table 3). Similarly, repriming stored primed seeds following controlled deterioration decreased viability (Table 4). The maximum enhancement of germination was obtained from a single priming treatment, and additional priming treatments either had no effect or decreased viability and vigor (Tables 3 and 4).

Some muskmelon seed lots germinate better under mild water stress than in water (Dunlap, 1988; Welbaum et al., 1990). At 30C, primed muskmelon seeds germinated to a higher percentage at -0.2 $\mathrm{MPa} \Psi$ than in water while nonprimed seeds did not, suggesting that the combined effects of priming and storage increased the sensitivity of muskmelon seeds to germination in water at high temperatures (Table 1). Muskmelon seeds are not as sensitive to high $\Psi$ at lower temperatures explaining why the phenomena was only observed at 30C (Dunlap, 1988). The physiological basis of sensitivity to high water remains poorly understood, but priming

Fig. 2. The force required to penetrate primed $(\boldsymbol{)})$, nonprimed $(\bigcirc)$, and boiled ( $\mathbf{\square})$ muskmelon seed pieces during imbibition before and after $(\boldsymbol{\Delta})$ germination measured using an Instron Universal Testing Machine. First radicle emergence began $25 \mathrm{~h}$ after the start of imbibition for primed seeds and at $28 \mathrm{~h}$ for nonprimed seeds. Error bars are \pm SE when larger than the symbols. 
apparently contributes to the development of the phenomena during long-term storage.

Muskmelon seeds germinate when the turgor in the embryonic axis exceeds the yield threshold for radicle growth (Welbaum et al., 1995). The threshold for germination is a combination of the yield threshold of the perisperm envelope, which surrounds the embryo, plus the yield threshold of the radicle tissue itself(Welbaum et al., 1995). Since priming weakened the perisperm envelope tissue (Fig. 2), primed seeds germinated faster because they reached the yield threshold earlier during imbibition than nonprimed seeds. Therefore, priming increases the rate of muskmelon seed germination by weakening the perisperm envelope. After the initial priming treatment, additional priming caused no further enhancement because further weakening of the perisperm was not possible (Table 3 ).

Seeds germinate best immediately after osmotic priming. If long-term storage is necessary before planting, seeds should be primed as close to the planting date as possible. The results of both long-term storage experiments and controlled deterioration tests show that osmotically primed muskmelon seeds exhibit decreased storage life compared to nonprimed seeds.

\section{Literature Cited}

Alvarado, A.D. and K.J. Bradford. 1988. Priming and storage of tomato (Lycopersicon Lycopersicum) seeds. I. Effects of storage temperature on germination rate and viability. Seed Sci. Technol. 16:601-612.

Argerich, C.A., K.J. Bradford, and A.M. Tarquis. 1989. The effects of priming and ageing on resistance to deterioration of tomato seeds. J. Expt. Bot. 40:593-598.

Atherton, J.G. and A.M. Farooque. 1983. High temperature and germination in spinach. II. Effects of osmotic priming. Sci. Hort. 19:221-227.

Bradford, K.J. 1986. Manipulation of seed water relations via osmotic priming to improved germination under stress conditions. HortScience 21:1105-1112.

Bradford, K.J., D.M. May, B.J. Hoyle, Z.S. Skibinski, S.J. Scott, and K.B. Tyler. 1988. Seed and soil treatments to improve emergence of muskmelon from cold or crusted soils. Crop Sci. 28:1001-1005.

Burgass, R.W. and A.A. Powell. 1984. Evidence for repair processes in the invigoration of seeds by hydration. Ann. Bot. 53:753-757.

Dearman, J., P.A. Brocklehurst, and R.L.K. Drew. 1986. Effects of osmotic priming and aging on onion seed germination. Ann. Appl. Biol. 108:639-648.

Dearman, J., P.A. Brocklehurst, and R.L.K. Drew. 1987a. Effects of osmotic priming and aging on the germination and emergence of carrot and leek seed. Ann. Appl. Biol. 111 717-722.

Dearman, J., R.L.K. Drew, and P.A. Brocklehurst. 1987b. Effect of osmotic priming, rinsing and storage on the germination and emergence of carrot seed. Ann. Appl. Biol. 111:723-727.

Dunlap, J.R. 1988. Effects of temperature and water potential on the germination of muskmelon cultivars. Ann. Appl. Biol. 112:187-194.

Ellis, R.H. and E.H. Roberts. 1981. The quantification of ageing and survival in orthodox seeds. Seed Sci. Technol. 9:373-409.

Finney, D.J. 1970. Probit analysis. 3rd ed. Cambridge Univ. Press, Cambridge.

International Seed Testing Association. 1985. International rules for seed testing. Seed Sci. Technol. 13:338-341.

Khan, A.A. 1992. Preplant physiological seed conditioning. Hort. Rev. 14:131-181.

Michel, B.E. 1983. Evaluation of the water potentials of solutions of polyethylene glycol 8000 both in the absence and presence of other solutes. Plant Physiol. 72:66-70.

Nath, S., P. Coolbear, and J.G. Hampton. 1991. Hydration-dehydration treatments to protect or repair stored karamu wheat seeds. Crop Sci. 31:822-826.

Nerson, H. and A. Govers. 1986. Salt priming of muskmelon seeds for low-temperature germination. Sci. Hort. (Amsterdam) 28:85-91.

Owen, P.L. and W.G. Pill. 1994. Germination of osmotically primed asparagus and tomato seeds after storage up to three months. J. Amer. Soc. Hort. Sci. 119:636-641.

Rao, N.K., E.H. Roberts, and R.H. Ellis. 1987. The influence of pre and post-storage hydration treatments on chromosomal aberrations, seedling abnormalities, and viability of lettuce seeds. Ann. Bot. 60:97-108.

Tarquis, A.M. and K.J. Bradford. 1992. Prehydration and priming treatments that advance germination also increase the rate of deterioration of lettuce seeds. J. Expt. Bot. 43:307-317.

Ward, F.H. and A.A. Powell. 1983. Evidence for repair processes in onion seeds during storage at high seed moisture contents. J. Expt. Bot. 34:277-282.

Welbaum, G.E. and K.J. Bradford. 1990. Water relations of seed development and germination in muskmelon (Cucumis melo L.). IV. Characteristics of the perisperm during seed development. Plant Physiol. 92:10381045.

Welbaum, G.E., T. Tissaoui, and K.J. Bradford. 1990. Water relations of seed development and germination in muskmelon (Cucumis melo L.). III. Sensitivity of germination to water potential and abscisic acid during development. Plant Physiol. 92:1029-1037.

Welbaum, G.E. and K.J. Bradford. 1991a. Water relations of seed development and germination in muskmelon (Cucumis melo L.). VI. Influence of priming on germination responses to temperature and water potential during seed development. J. Expt. Bot. 42:393-399.

Welbaum, G.E. and K.J. Bradford. 1991b. Water relations of seed development and germination in muskmelon (Cucumis melo L.). VII. Influence of after-ripening and ageing on germination responses to temperature and water potential. J. Expt. Bot. 42:1137-1145.

Welbaum, G.E., W.J. Muthui, J.H. Wilson, R.L. Grayson, and R.D. Fell. 1995. Weakening of muskmelon perisperm envelope tissue during germination. J. Expt. Bot. 46:391-400. 